\title{
Detrimental effects of specific Periodontopathic bacterial infection on tachyarrhythmia compared to Bradyarrhythmia
}

Norio Aoyama', Jun-ichi Suzuki ${ }^{2,3^{*}}$ D, Naho Kobayashi ${ }^{4}$, Tomoya Hanatani ${ }^{5}$, Norihiko Ashigaki ${ }^{6}$, Asuka Yoshida ${ }^{4}$, Yuka Shiheido ${ }^{4}$, Hiroki Sato ${ }^{4}$, Hidetoshi Kumagai ${ }^{2}$, Yuichi Ikeda ${ }^{7}$, Hiroshi Akazawa ${ }^{7}$, Issei Komuro ${ }^{7}$, Masato Minabe ${ }^{1}$, Yuichi Izumi ${ }^{4}$ and Mitsuaki Isobe ${ }^{3}$

\begin{abstract}
Background: Tachyarrhythmia (TA) and bradyarrhythmia (BA) are cardiac rhythm disorders that result in the decline of quality of life. While patients with periodontitis are at a high risk of cardiovascular disease (CVD), little causal information between TA and BA has been provided to date. To assess the relationship, periodontal bacterial infection in patients with TA or BA was evaluated.

Methods: The subjects were patients with TA $(n=98)$ or BA $(n=40)$ who attended Tokyo Medical and Dental University hospital. Periodontal and blood examinations were performed. Periodontopathic bacterial existence in saliva was evaluated.

Results: We found that specific periodontopathic bacteria, Porphyromonas gingivalis and Prevotella intermedia, were highly detected in saliva from TA patients compared to BA subjects. The rates of hypertension and dyslipidemia were comparable between the two groups.
\end{abstract}

Conclusion: Specific periodontal bacterial infection might affect TA progression.

Keywords: Arrhythmia, Periodontal disease, Bacteria

\section{Background}

Periodontitis is an infectious oral disease that leads to destruction of the supporting tissues of teeth and finally induces loss of teeth. It is characterized as a chronic infection with periodontal bacteria. Many reports have shown that periodontal disease has a high prevalence around the world [1,2]. Periodontitis is suspected as a possible risk factor for some systemic diseases including cardiovascular disease (CVD) [3]. Because CVD is an important cause of death, its prevention and treatment are significant health issues. Many studies indicated that

\footnotetext{
* Correspondence: junichisuzuki-circ@umin.ac.jp

${ }^{2}$ Department of Advanced Clinical Science and Therapeutics, The University

of Tokyo, 7-3-1 Hongo, Bunkyo-ku, Tokyo 113-8655, Japan

${ }^{3}$ Department of Cardiovascular Medicine, Tokyo Medical and Dental

University, 1-5-45 Yushima, Bunkyo-ku, Tokyo 113-8549, Japan

Full list of author information is available at the end of the article
}

patients with periodontal disease had a high risk for CVD events such as coronary artery disease (CAD), stroke and peripheral arterial disease [4-10].

Tachyarrhythmia (TA) and bradyarrhythmia (BA) are cardiac rhythm disorders that result in the decline of quality of life [11]. While patients with periodontitis are at a high risk of CVD, little causal information between arrhythmia and periodontitis has been provided to date. To assess the relationship, periodontal bacterial infection in patients with TA or BA were evaluated.

\section{Methods}

Study population

Subjects who were 71-90 years old were recruited from CVD patients with TA or BA in the Department of Cardiovascular Medicine in Tokyo Medical and Dental University Hospital between May 2012 and August 2015. 
One hundred and 38 subjects participated in this study and were subdivided into two age groups (71-80 year-old and 81-90 year-old). Excluded in this study were individuals who had a history and/or presence of other infectious diseases or did not consent to the participation. The Ethics Committees of the School of Medicine and the School of Dentistry, Tokyo Medical and Dental University approved the present study (744), and the protocol conformed to the Helsinki Declaration of 1975, as revised in 2013. Written informed consent was provided by the subjects.

\section{Medical examination}

Medical doctors recorded medical and smoking history. TA and BA were diagnosed by electrocardiogram. Subjects who were diagnosed and/or treated as diabetes mellitus (DM), hypertension (HT) and dyslipidemia (DL) were recorded. Peripheral blood samples were obtained and level of C-reactive protein (CRP) was determined.

\section{Periodontal examination}

Trained periodontists counted the number of residual teeth. Probing pocket depth (PPD), clinical attachment level (CAL) and bleeding on probing (BOP) at six points per tooth (buccal-mesial, mid-buccal, buccal-distal, lingualmesial, mid-lingual and lingual-distal) on an upper right molar, an upper incisor, an upper left molar, a lower right molar, a lower incisor and a lower left molar were measured with a manual probe (PCP-UNC 15, Hu-Friedy, Chicago, IL, USA). When the representative tooth was missing, next tooth was used.

\section{Detection of bacteria}

We obtained unstimulated saliva and used DNeasy Blood and Tissue kit (Qiagen, Tokyo, Japan) according to manufacturer's instructions to extract bacterial DNA. Real-time polymerase chain reaction (PCR) was used to detect three major periodontal bacteria, Porphyromonas gingivalis ( $P$. gingivalis), Aggregatibacter actinomycetemcomitans (A. actinomycetemcomitans) and Prevotella intermedia ( $P$. intermedia). The real-time PCR was performed and specific primers for each bacterium were used as previously described [12].

\section{Statistical analysis}

Numerical data was presented as means \pm standard deviation (SD). Student's $t$-test was used to compare numerical values such as age, CRP, teeth number, PPD, CAL and BOP. Chi-square test was performed to compare dichotomous variables such as sex, smoker rate, positive rates of DM, $\mathrm{HT}$ and DL and bacterial detection rates. Wilcoxon test was used to compare bacterial counts, because bacterial counts were not normally distributed. We used JMP 9.0.3
(SAS Institute Inc., Cary, NC, USA) for all statistical analyses and considered values of $p<0.05$ significant.

\section{Results}

\section{Characteristics of the patients}

The characteristics of the subjects in the present study are shown in Table 1. There was no statistical difference of age, sex, smoking rate, HT, DL and CRP between the groups. Prevalence of DM was higher in the TA group compared with the BA group in 81-90 year-old patients, but not in 71-80 year-old patients.

\section{Periodontal conditions}

The number of missing teeth was comparable between the two arrhythmia groups of the same age categories (Table 2). There was no statistical difference of mean PPD, CAL and BOP rate between the groups.

\section{Bacterial counts}

The counts of $P$. intermedia in the TA group increased in comparison to the BA group in 71-80 year-old patients (Table 3). The TA group also had an increased amount of $P$. gingivalis compared to the BA group in 81-90 year-old patients (Table 3 ). The counts of $A$. actinomycetemcomitans were comparable between the two groups. We also showed a positive rate of $P$. intermedia (Table 4). The TA group had an increased detection rate of compared to the BA group in 71-80 year-old patients.

Table 1 Characteristics of the subjects

\begin{tabular}{|c|c|c|}
\hline Group & Bradyarrhythmia & Tachyarrhythmia \\
\hline \multicolumn{3}{|c|}{ (A) 71-80 year-old patients } \\
\hline Number & 30 & 79 \\
\hline Age & $75.1+/-2.4$ & $74.3+/-2.4$ \\
\hline Sex (Female \%) & 23 & 27 \\
\hline Smoking [\%] & 37 & 43 \\
\hline Diabetes [\%] & 47 & 32 \\
\hline Hypertension [\%] & 77 & 71 \\
\hline Dyslipidemia [\%] & 50 & 38 \\
\hline CRP $[\mathrm{mg} / \mathrm{dL}]$ & $0.38+/-0.56$ & $0.36+/-0.93$ \\
\hline \multicolumn{3}{|c|}{ (B) 81-90 year-old patients } \\
\hline Number & 10 & 19 \\
\hline Age & $83.5+/-2.9$ & $83.2+/-2.2$ \\
\hline Sex (Female \%) & 30 & 42 \\
\hline Smoking [\%] & 10 & 32 \\
\hline Diabetes [\%] & 0 & $26^{*}$ \\
\hline Hypertension [\%] & 70 & 89 \\
\hline Dyslipidemia [\%] & 20 & 42 \\
\hline CRP [mg/dL] & $0.79+/-2.12$ & $1.20+/-3.21$ \\
\hline
\end{tabular}

${ }^{*} p<0.05$ between the groups 
Table 2 Periodontal condition

\begin{tabular}{lll}
\hline Group & Bradyarrhythmia & Tachyarrhythmia \\
\hline (A) $71-80$ year-old patients & & \\
Number of missing teeth & $12.9+/-9.2$ & $14.4+/-9.5$ \\
PPD [mm] & $2.44+/-0.52$ & $2.56+/-0.68$ \\
CAL [mm] & $3.10+/-1.11$ & $3.57+/-1.20$ \\
BOP [\%] & $16+/-22$ & $22+/-24$ \\
(B) $81-90$ year-old patients & & \\
Number of missing teeth & $17.1+/-9.7$ & $16.7+/-8.4$ \\
PPD [mm] & $2.41+/-0.30$ & $2.39+/-0.55$ \\
CAL [mm] & $3.65+/-1.09$ & $3.34+/-1.06$ \\
BOP [\%] & $17+/-17$ & $12+/-20$ \\
\hline
\end{tabular}

\section{Discussion}

In this study, we found that specific periodontopathic bacteria, $P$. gingivalis and $P$. intermedia, were highly detected in the TA subjects compared to the BA subjects.

\section{Periodontitis affects arrhythmia}

It is well known that there is a relationship between periodontitis and CVD. However, there are few papers to show the association between arrhythmia and periodontitis. It is well recognized that ischemic stroke is frequently induced by TA. Clinically, a recent casecontrol study showed that high levels of periodontal clinical attachment loss, gingivitis and radiographic bone loss were independently associated with stroke, while the etiology of the stroke was not indicated [13]. On the other hand, Holm-Pedersen et al. demonstrated that there might be a link between active root caries and cardiac arrhythmias in elderly persons, while there was no association between periodontal disease and arrhythmia in the study [14]. In an animal model, Yu et al. showed the effect of periodontitis on susceptibility to atrial fibrillation, which is a major TA.
Periodontitis was induced by tying 2-0 silk ligatures at the second premolar of mandibula in adult mongrel canines. Electrophysiologic evaluation was performed to assess atrial refractoriness and atrial fibrillation inducibility. They found that periodontitis induced inflammatory responses in atrial myocardium, which disturbed the structural and electrophysiologic properties of the atrium and facilitated atrial fibrillation [15]. Therefore, periodontitis may deteriorate TA such as atrial fibrillation.

\section{Specific Periodontopathic bacteria infection may deteriorate TA}

There are a limited number of reports to evaluate the influence of systemic periodontal pathogen infections on TA and/or stroke. Hosomi et al. demonstrated a relationship between serum antibodies against periodontal pathogens and ischemic stroke. They evaluated patients with acute ischemic stroke and patients without previous stroke or stroke subtype. The results showed that the serum-antibody level of $P$. intermedia was significantly higher in athero-thrombotic stroke patients than in patients with no previous stroke. Serum antibody against $P$. gingivalis was also significantly associated with atrial fibrillation. They concluded that infection with specific periodontal bacteria was associated with stroke and atrial fibrillation [16]. Pussinen et al. also showed serological evidence that a chronic infection caused by $P$. gingivalis and $A$. actinomycetemcomitans was associated with stroke incidence in prospective case-control studies $[17,18]$, while the etiology of the stroke was not clarified. These previous studies suggested that periodontal pathogens such as $P$. gingivalis and $P$. intermedia may have some crucial effects on stroke and/or TA. The mechanisms connecting periodontal infection and TA are not clear, but long-term systemic exposure to periodontal pathogens may influence cardiac homeostasis.

Table 3 Bacterial counts in saliva

\begin{tabular}{llll}
\hline & Bradyarrhythmia & Tachyarrhythmia & $P$ \\
\hline (A) $71-80$ year-old patients & & & $1.4 \times 10^{5}\left(3.0 \times 10^{2}, 3.7 \times 10^{6}\right)$ \\
P. gingivalis & $5.5 \times 10^{3}\left(0,4.8 \times 10^{5}\right)$ & $0(0,0)$ & 0.1118 \\
A. actinomycetemcomitans & $0(0,0)$ & $0\left(0,8.4 \times 10^{2}\right)$ & 0.8187 \\
P. intermedia & $0(0,0)$ & $6.8 \times 10^{6}\left(3.7 \times 10^{4}, 2.3 \times 10^{7}\right)$ & $0.0193^{*}$ \\
(B) 81 -90 year-old patients & & $0\left(0,1.1 \times 10^{2}\right)$ & $0.0062^{*}$ \\
P. gingivalis & $6.7 \times 10^{2}\left(1.4 \times 10^{2}, 4.1 \times 10^{4}\right)$ & $0\left(0,7.0 \times 10^{3}\right)$ & 0.5630 \\
A. actinomycetemcomitans & $0(0,0)$ & &
\end{tabular}

Values are shown as median [counts/mL] (first and third quartile)

${ }^{*} p<0.05$ between the groups 
Table 4 Positive rate of bacteria in saliva

\begin{tabular}{|c|c|c|c|}
\hline & Bradyarrhythmia & Tachyarrhythmia & $P$ \\
\hline \multicolumn{4}{|l|}{ (A) 71-80 year-old patients } \\
\hline P. gingivalis & $59 \%$ & $80 \%$ & 0.0581 \\
\hline $\begin{array}{l}\text { A. } \\
\text { actinomycetemcomitans }\end{array}$ & $18 \%$ & $18 \%$ & 0.9473 \\
\hline P. intermedia & $9 \%$ & $35 \%$ & $0.0105^{\circ}$ \\
\hline \multicolumn{4}{|l|}{ (B) 81-90 year-old patients } \\
\hline P. gingivalis & $78 \%$ & $100 \%$ & 0.0713 \\
\hline $\begin{array}{l}\text { A. } \\
\text { actinomycetemcomitans }\end{array}$ & $11 \%$ & $20 \%$ & 0.5921 \\
\hline P. intermedia & $11 \%$ & $40 \%$ & 0.1415 \\
\hline
\end{tabular}

${ }^{*} p<0.05$ between the groups

\section{Conclusions}

In the present study, we revealed that specific periodontopathic bacteria, $P$. gingivalis and $P$. intermedia, were highly detected in subjects with TA compared to BA. Thus, we can conclude that specific periodontopathic bacterial infection may affect TA development. Generally, the elderly cardiovascular patients including arrhythmia patients have a higher prevalence of asymptomatic disorders than young patients. And also the elderly patients often have other systemic diseases. These factors may reduce statistical sensitivity of symptomatic arrhythmia. This may be a reason why elderly people positive for periodontal bacteria had decreased symptoms of TA or BA. Recently, we demonstrated that $P$. gingivalis influenced myocardial remodeling after ischemia [19]. Another study showed that $P$. intermedia might have some effects on cardiovascular disease in Marfan syndrome patients [20]. Thus, these two specific bacteria may affect TA through myocardial remodeling in clinical settings. Further investigation is needed to reveal the detailed causal relationship between arrhythmia and specific periodontopathic bacterial infection.

\section{Abbreviation}

A. actinomycetemcomitans: Aggregatibacter actinomycetemcomitans; BA: Bradyarrhythmia; BOP: Bleeding on probing; CAD: Coronary artery disease; CAL: Clinical attachment level; CRP: C-reactive protein; CVD: Cardiovascular disease; DL: Dyslipidemia; DM: Diabetes mellitus; HT: Hypertension; $P$. gingivalis: Porphyromonas gingivalis; $P$. intermedia: Prevotella intermedia; PCR: Polymerase chain reaction; PPD: Probing pocket depth; SD: Standard deviation; TA: Tachyarrhythmia

\section{Acknowledgements}

Not applicable.

\section{Funding}

This work was supported by JSPS KAKENHI Grant Numbers (JP25870198, JP15K20616, and JP16H05824), Ministry of Education, Culture, Sports, Science and Technology of Japan, Mitsui Life Insurance Research Foundation, Mitsui Sumitomo Marine Welfare Research Foundation, Geriatric Dental Research Foundation, Human Health Future Research Foundation, St. Luke's Hospital Research Foundation, Health Management Foundation, Taiyo Life Insurance Research Foundation, The 8020 Promotion Foundation, Terumo Science Foundation, Pfizer Health Research Foundation, General Health Promotion
Foundation, Suzuken Memorial Foundation, Health Science Center Foundation, Kobayashi International Scholarship Foundation, Banyu Life Science Foundation International, and Hakujikai Institute of Gerontology Foundation.

Availability of data and materials

Raw data supporting the results can be requested from the corresponding author.

\section{Authors' contributions}

$\mathrm{NAO}, J \mathrm{~S}, \mathrm{IK}, \mathrm{MM}, \mathrm{Ylz}$ and $\mathrm{Ml}$ conceived and designed the study. NAo, NK, TH, NAs, AY, YS, HS, HK, YIk, HA and MI participated in data acquisition. NAo and JS performed statistical analysis. All authors wrote and approved the final manuscript

Ethics approval and consent to participate

The Ethics Committees of the School of Medicine and the School of Dentistry, Tokyo Medical and Dental University approved the present study (744), and the protocol conformed to the Helsinki Declaration of 1975, as revised in 2013. Written informed consent was provided by the subjects.

Consent for publication

Not applicable.

Competing interests

The authors declare that they have no competing interests.

\section{Publisher's Note}

Springer Nature remains neutral with regard to jurisdictional claims in published maps and institutional affiliations.

\section{Author details}

${ }^{1}$ Division of Periodontology, Department of Oral Interdisciplinary Medicine, Graduate School of Dentistry, Kanagawa Dental University, 82 Inaokacho, Yokosuka, Kanagawa 238-8580, Japan. ${ }^{2}$ Department of Advanced Clinical Science and Therapeutics, The University of Tokyo, 7-3-1 Hongo, Bunkyo-ku, Tokyo 113-8655, Japan. ${ }^{3}$ Department of Cardiovascular Medicine, Tokyo Medical and Dental University, 1-5-45 Yushima, Bunkyo-ku, Tokyo 113-8549, Japan. ${ }^{4}$ Department of Periodontology, Graduate School of Medical and Dental Sciences, Tokyo Medical and Dental University, 1-5-45 Yushima, Bunkyo-ku, Tokyo 113-8549, Japan. ${ }^{5}$ Division of Periodontology, Kyushu Dental University, 2-6-1 Manazuru, Kokurakita-ku, Kitakyushu, Fukuoka 803-8580, Japan. ${ }^{6}$ Department of Oral Microbiology, Tsurumi University, 2-1-3 Tsurumi, Tsurumi-ku, Yokohama, Kanagawa 230-8501, Japan. ${ }^{7}$ Department of Cardiovascular Medicine, The University of Tokyo, 7-3-1 Hongo, Bunkyo-ku, Tokyo 113-8655, Japan.

Received: 13 July 2017 Accepted: 13 October 2017

Published online: 17 October 2017

\section{References}

1. Pihlstrom BL, Michalowicz BS, Johnson NW. Periodontal diseases. Lancet. 2005;366:1809-20.

2. Petersen PE. The world oral health report 2003: continuous improvement of oral health in the 21 st century - the approach of the WHO global oral health Programme. Community Dent Oral Epidemiol. 2003;31(Suppl 1):3-23.

3. Zadik Y, Bechor R, Galor S, Justo D, Heruti RJ. Erectile dysfunction might be associated with chronic periodontal disease: two ends of the cardiovascular spectrum. J Sex Med. 2009;6:1111-6.

4. Schmitt A, Carra MC, Boutouyrie P, Bouchard P. Periodontitis and arterial stiffness: a systematic review and meta-analysis. J Clin Periodontol. 2015;42: 977-87.

5. Humphrey LL, Fu R, Buckley DI, Freeman M, Helfand M. Periodontal disease and coronary heart disease incidence: a systematic review and Metaanalysis. J Gen Intern Med. 2008:23:2079-86.

6. Bahekar AA, Singh S, Saha S, Molnar J, Arora R. The prevalence and incidence of coronary heart disease is significantly increased in periodontitis: a metaanalysis. Am Heart J. 2007;154:830-7

7. Hujoel PP, Drangsholt M, Spiekerman C, DeRouen TA. Periodontal disease and coronary heart disease risk. JAMA. 2000;284:1406-10.

8. DeStefano F, Anda RF, Kahn HS, Williamson DF, Russell CM. Dental disease and risk of coronary heart disease and mortality. BMJ. 1993;306:688-91. 
9. Beck JD, Offenbacher S. The association between periodontal diseases and cardiovascular diseases: a state-of-the-science review. Ann Periodontol. 2001;6:9-15.

10. Chen $Y W$, Umeda M, Nagasawa $T$, Takeuchi $Y$, Huang $Y$, Inoue $Y$, Iwai $T$, Izumi $Y$, Ishikawa I. Periodontitis may increase the risk of peripheral arterial disease. Eur J Vasc Endovasc Surg. 2008;35:153-8.

11. Aliot E, Botto GL, Crijns HJ, Kirchhof P. Quality of life in patients with atrial fibrillation: how to assess it and how to improve it. Europace. 2014;16:787-96.

12. Maeda H, Fujimoto C, Haruki Y, Maeda T, Kokeguchi S, Petelin M, Arai H, Tanimoto I, Nishimura F, Takashiba S. Quantitative real-time PCR using TaqMan and SYBR green for Actinobacillus actinomycetemcomitans, Porphyromonas gingivalis, Prevotella intermedia, tetQ gene and total bacteria. FEMS Immunol Med Microbiol. 2003;39:81-6.

13. Dörfer CE, Becher H, Ziegler CM, Kaiser C, Lutz R, Jorss D, Lichy C, Buggle F, Bultmann S, Preusch M, Grau AJ. The association of gingivitis and periodontitis with ischemic stroke. J Clin Periodontol. 2004;31:396-401.

14. Holm-Pedersen P, Avlund K, Morse DE, Stoltze K, Katz RV, Viitanen M, Winblad B. Dental caries, periodontal disease, and cardiac arrhythmias in community-dwelling older persons aged 80 and older: is there a link? J Am Geriatr Soc. 2005;53:430-7.

15. Yu G, Yu Y, Li YN, Shu R. Effect of periodontitis on susceptibility to atrial fibrillation in an animal model. J Electrocardiol. 2010:43:359-66.

16. Hosomi N, Aoki S, Matsuo K, Deguchi K, Masugata H, Murao K, Ichihara N, Ohyama H, Dobashi H, Nezu T, Ohtsuki T, Yasuda O, Soejima H, Ogawa H, Izumi Y, Kohno M, Tanaka J, Matsumoto M. Association of serum antiperiodontal pathogen antibody with ischemic stroke. Cerebrovasc Dis. 2012; 34:385-92.

17. Pussinen PJ, Alfthan G, Rissanen $H$, Reunanen A, Asikainen S, Knekt P. Antibodies to periodontal pathogens and stroke risk. Stroke. 2004;35:2020-3.

18. Pussinen PJ, Alfthan G, Jousilahti P, Paju S, Tuomilehto J. Systemic exposure to Porphyromonas gingivalis predicts incident stroke. Atherosclerosis. 2007;193:222-8.

19. Shiheido $Y$, Maejima Y, Suzuki J, Aoyama N, Kaneko M, Watanabe R, Sakamaki Y, Wakayama K, Ikeda Y, Akazawa H, Ichinose S, Komuro I, Izumi Y, Isobe M. Porphyromonas gingivalis, a periodontal pathogen, enhances myocardial vulnerability, thereby promoting post-infarct cardiac rupture. J Mol Cell Cardiol. 2016;99:123-37.

20. Suzuki J, Imai Y, Aoki M, Fujita D, Aoyama N, Tada Y, Wakayama K, Akazawa H, Izumi Y, Isobe M, Komuro I, Nagai R, Hirata Y. Periodontitis in cardiovascular disease patients with or without Marfan syndrome -a possible role of Prevotella intermedia. PLoS One. 2014;9:e95521

\section{Submit your next manuscript to BioMed Central and we will help you at every step:}

- We accept pre-submission inquiries

- Our selector tool helps you to find the most relevant journal

- We provide round the clock customer support

- Convenient online submission

- Thorough peer review

- Inclusion in PubMed and all major indexing services

- Maximum visibility for your research

Submit your manuscript at www.biomedcentral.com/submit 